\title{
O DIREITO UNIVERSAL À EDUCAÇÃO: silêncios, riscos e possibilidades"
}

\section{THE UNIVERSAL RIGHT TO EDUCATION: silences, risks and possibilities}

\author{
Tristan McCowan**
}

\begin{abstract}
Resumo
Apesar de haver uma considerável literatura acerca da educação no contexto da legislação internacional de direitos, pouco se discute sobre os sentidos fundamentais da educação, a sua natureza e escopo. Este artigo apresenta uma exploração teórica dessa questão e leva a uma reavaliação normativa. Primeiramente, o artigo avalia como o direito à educação é expresso na Declaração Universal dos Direitos Humanos, identificando as suas limitações no que se refere ao foco na escolaridade primária. Outros candidatos a constituírem a base desse direito são avaliados, como os resultados da aprendizagem e o engajamento em processos educacionais, vindo o último a ser considerado a base mais sólida. No entanto, as implicações da escolaridade formal para as desigualdades sociais não podem ser ignoradas. Em razão disso, propõe-se uma expressão desse direito em duas vias, envolvendo o acesso tanto a uma aprendizagem significativa quanto a instituições que oferecem vantagem posicional.
\end{abstract}

Palavras-chave: Educação para todos. Direitos humanos. Direito à Educação.

\begin{abstract}
Despite the considerable literature on subject of education in international rights law, there has been little discussion of the fundamental meanings of education in question, its nature and its scope. This article presents a theoretical exploration of the question, leading to a normative reassessment. The article first assesses the expression of the right in the Universal Declaration of Human Rights, identifying limitations in its focus on primary schooling. Other candidates for a basis for the right - namely learning outcomes and engagement in educational processes - are then assessed, and the latter is found to provide the most coherent foundation. Nevertheless, the implications of formal schooling for social inequalities cannot be ignored. Consequently, a two-pronged expression of the right is proposed, involving access both to meaningful learning and to institutions that confer positional advantage.
\end{abstract}

Keywords: Education for all. Human rights. Right to education.

\section{Introdução}

Desde meados do século $X X$, tem-se observado em todo o mundo uma enorme expansão do acesso à educação, com vários países próximos de universalizar o Ensino Fundamental e alguns, o Ensino Médio. Contudo, algumas regiões do globo estão muito aquém de garantir sequer a universalização do Ensino Fundamental. Cerca de 75 milhões de crianças encontram-se fora da escola - quase metade delas na África Subsaariana - e muitas frequentam a sala de aula esporadicamente, não chegando a completar a sua formação. Entre as que estão fora da escola, 55\% são meninas, e um número desproporcional compreende os seguintes grupos: crianças com algum tipo de deficiência, crianças de rua ou trabalhadoras e crianças que vivem em favelas ou áreas rurais distantes. Além disso, $750 \mathrm{mi}-$ Ihões de adultos não possuem alfabetização básica e o acesso à educação de nível médio no mundo é da ordem de apenas 58\%. Na África Subsaariana, somente um quarto dos jovens na faixa etária correspondente ao ensino médio está matriculado (UNESCO, 2008).

A maioria das pessoas concordaria que essa situação é muito preocupante. A desigualdade das oportunidades educacionais ao redor do mundo e a já compreendida importância da educação para o

\footnotetext{
* Tradução de Roberto Monteiro de Lima, com revisão de Jefferson Mainardes (PPGE/UEPG).

** Professor do Institute of Education, University of London. E-mail: t.mccowan@ioe.ac.uk
} 
desenvolvimento geral de uma nação fizeram com que essa questão viesse a ser apreciada em âmbito internacional. A busca pelo acesso universal ganhou destaque com as Conferências Mundiais sobre Educação Para Todos, realizadas em Jomtien (1990) e Dakar (2000), os Objetivos de Desenvolvimento do Milênio e programas subsequentes, como a Fast Track Initiative ${ }^{1}$.

Embora os esforços para a expansão do acesso à educação tenham tido motivações diversas, como a teoria do capital humano e a concepção de construção nacional, o movimento "Educação Para Todos", em seu conjunto, tem por base o direito de todas as crianças à educação, o qual fora previamente garantido pela Declaração Universal dos Direitos Humanos (DUDH), de 1948. Mas a que de fato se refere o direito à educação? Estaria relacionado ao acesso a instituições de ensino, a uma forma específica de experiência educacional ou a algum efeito educacional?

Levando-se em conta a significativa literatura sobre o direito à educação e Educação Para Todos, é surpreendente que as discussões acerca da natureza da educação contemplem esse tópico de maneira tão escassa. O objetivo deste artigo é abordar essa omissão analisando até que ponto as escolas são uma condição necessária e suficiente para a realização desse direito. Deve-se atentar para o fato de que o direito à educação não é como os direitos a vestuário ou moradia, por exemplo, pois nesses casos é relativamente fácil averiguar se os direitos estão sendo cumpridos ou não. São três os aspectos da educação que geram complexidades de especial relevância. Em primeiro lugar, a educação existe de formas muito variadas, algumas delas podendo ser até mesmo negativas, embora nós tenhamos a opção de usar o termo "educação" somente para casos positivos. Em segundo lugar, a educação vai além de si mesma, pois é tanto uma preparação para outras atividades quanto uma experiência potencialmente enriquecedora por si só, de modo que decisões sobre metas externas também precisam ser tomadas. Em terceiro lugar, os alunos não necessariamente levam consigo o que lhes foi apresentado na sala de aula (e é bastante difícil prever o que exatamente eles levarão consigo).

Por isso, deve-se dispensar muita atenção não somente à implementação do direito à educa-

\footnotetext{
${ }^{1}$ Fast Track Initiative é uma parceria global para ajudar países menos desenvolvidos atingirem os objetivos de desenvolvimento do milênio e o objetivo da "Educação para Todos" que todos os alunos completem o ciclo da educação primária até 2015. O FTI é uma plataforma para colaboração nos níveis global e nacional. Por meio do FTI, os países em desenvolvimento comprometemse a definir e implementar planos educacionais enquanto que os patrocinadores comprometem-se a garantir recursos para esses planos (Nota do revisor)
}

ção como à sua conceituação. Nós só poderemos ter uma imagem clara daquilo a que o direito à educação se aplica quando avaliarmos as justificativas para o mesmo e estimarmos o nosso progresso na sua realização. Neste artigo, a questão é tratada num viés predominantemente teórico, mas se recorre a casos empíricos para efeito de ilustração. Após discutir brevemente a noção de "direito", o artigo dá início a uma análise do direito à educação baseando-se na definição expressa na DUDH, de modo a identificar limitações referentes ao seu foco na escolaridade fundamental. Em seguida, o artigo avalia outros candidatos a constituírem a base desse direito, a saber, os resultados da aprendizagem e o engajamento em processos educacionais. Por um lado, destacam-se as vantagens desses candidatos sobre o foco institucional; por outro, identificam-se algumas dificuldades significativas representadas por eles. Finalmente, propõe-se que o direito à educação tenha dois componentes: um relacionado à experiência educacional e o outro, à vantagem posicional. Esta proposta implica tanto uma reexpressão desse direito no âmbito das declarações internacionais quanto uma reorientação da pesquisa sobre Educação Para Todos.

\section{Direitos universais}

Conforme foi mencionado, vários estudos (por exemplo, BEITER, 2006; FRIBOULET et al., 2007; HODGSON, 1998; TOMASEVSKI, 2003; WRINGE, 1986) fizeram amplas explorações das bases legais do direito à educação, bem como das suas justificativas e da sua implementação. Contudo, à exceção de poucos (por exemplo, SPRING, 2000; VANDENBERG, 1990), esses estudos dedicaram pouco espaço à discussão dos possíveis sentidos da educação². Com demasiada frequência, a educação é entendida como sinônimo de escolaridade, e mesmo assim não se reconhecem as complexidades da experiência escolar. O foco deste estudo, portanto, são os aspectos educacionais dessa questão e não os aspectos relativos a um conceito mais amplo de direitos e da sua universalidade. No entanto, algo precisa ser dito sobre o entendimento de direitos expresso neste artigo. Refiro-me a um direito "universal", por oposição aos direitos acordados a cidadãos desta ou daquela nação. Direitos universais são antes direitos morais do que direitos legais, embora tenham estatuto oficial por meio de declarações não vinculativas, como a DUDH, e em alguns casos, como no da Convenção

\footnotetext{
${ }^{2}$ A chamada literatura sobre os "4 As" - availability, accessibility, acceptability e adaptability [disponibilidade, acessibilidade, aceitabilidade e adaptabilidade, respectivamente] (por exemplo, TOMASEVSKI, 2003, 2006) estipula critérios pelos quais podemos julgar a equidade e a eficiência da oferta de educação.
} 
das Nações Unidas sobre os Direitos da Criança (CNUDC), são transformados em tratados com força legal. Neste texto, considero "direitos universais" e "direitos humanos" como sinônimos. No caso dos direitos humanos, a ênfase reside no fato de que todos os seres humanos os possuem igualmente, e somente os seres humanos. De maneira geral, sigo a definição de direitos humanos dada por Pogge (2002, p. 58):

\begin{abstract}
O comprometimento com os direitos humanos pressupõe a percepção de que as pessoas que tiveram ou que potencialmente terão a capacidade de se engajarem em debates e práticas morais possuem certas necessidades básicas, as quais geram sérias demandas morais. O objeto de cada uma dessas necessidades básicas é o objeto de um direito humano. Reconhecer que tais necessidades básicas geram direitos humanos pressupõe o comprometimento em se opor ao desrespeito para com as mesmas por parte da sua própria sociedade (e de outros sistemas sociais afins dos quais se faz parte).
\end{abstract}

Neste artigo, discuto a educação como um direito moral, mas me oriento para estabelecer uma formulação que possa ser expressa e universalmente aceita em declarações como a DUDH. Ainda que a viabilidade em todos os contextos não deva restringir a expressão dos direitos (SEN, 2004), devese atentar para os modos como os países podem transpor esse conceito para a prática.

\section{O direito à educação na Declaração Universal dos Direitos Humanos}

O direito à educação encontra-se claramente previsto em acordos internacionais. Além de integrar a DUDH, esse direito foi reforçado em vários pactos, convenções, declarações e modelos relacionados à educação, direitos humanos e direitos da criança nas seis décadas que se passaram desde a sua assinatura. Ainda assim, o direito legal à educação revela-se uma estranha miscelânea: é específico e prescritivo em relação a alguns aspectos e omisso em relação a outros. Surpreendentemente, é específico no tocante às formas institucionais que devem garantir a educação e à duração desta, mas, a despeito de algumas recomendações gerais sobre objetivos, não é específico quanto aos tipos de processos realizados nessas instituições. Nesta seção, defendo a ideia de que o direito à educação deve ser exatamente o oposto disso.

A análise aqui apresentada concentra-se no artigo da DUDH pertinente à questão. Algumas modificações podem ser notadas na Declaração dos Direitos da Criança (1959), no Pacto Internacional sobre os Direitos Econômicos, Sociais e Culturais (PIDESC, 1966) e na Convenção sobre os Direitos da Criança (CDC, 1989). Relatos muito mais substanciais sobre educação constam dos Comentários Gerais ao Artigo 13 do PIDESC (1999) e ao Artigo 29 da Convenção das Nações Unidas sobre os Direitos da Criança (2001). Tratamentos mais extensos também podem ser encontrados nos documentos oriundos das Conferências Mundiais sobre Educação Para Todos, realizadas em Jomtien (1990) e Dakar (2000). De modo geral, tais inclusões permanecem fiéis aos princípios estabelecidos no documento original da DUDH; por isso, bem como por economia, a presente análise limita-se à declaração inicial.

O Artigo 26 da DUDH divide-se em três partes:

a) Toda pessoa tem direito à instrução. A instrução será gratuita, pelo menos nos graus elementares e fundamentais. A instrução elementar será obrigatória. A instrução técnico-profissional será acessível a todos, bem como a instrução superior, esta baseada no mérito.

b) A instrução será orientada no sentido do pleno desenvolvimento da personalidade humana e do fortalecimento do respeito pelos direitos humanos e pelas liberdades fundamentais. A instrução promoverá a compreensão, a tolerância e a amizade entre todas as nações e grupos raciais ou religiosos, e coadjuvará as atividades das Nações Unidas em prol da manutenção da paz.

c) Os pais têm prioridade de direito na escolha do gênero de instrução que será ministrada a seus filhos.

Dois aspectos bastante polêmicos do direito à educação constantes da DUDH não são abordados neste texto. O primeiro refere-se ao terceiro parágrafo do artigo citado, a saber, a prioridade de direito que os pais têm de educar os filhos segundo as suas crenças (esse tópico foi investigado por Curren, 2009). O segundo é a afirmação de que a educação fundamental deve ser obrigatória. Trata-se de questões muito complexas que vão além da área de investigação deste estudo, cujo foco são as formas de educação às quais as pessoas podem (ou não) ter direitos, e não as questões de público e privado ou o equilíbrio de poder e os potenciais conflitos entre Estado, pais e outras partes interessadas.

Inicialmente, é importante observar que a existência de um direito à educação como esse em nível internacional é altamente desejável e que as pessoas que dão expressão escrita a esse e outros direitos têm de maneira geral prestado um grande serviço ao criarem uma forma que ao mesmo tempo representa a reivindicação junto ao Estado e a inclusão de conceitos oriundos de culturas diversas. Contudo, há alguns elementos problemáticos nesse cenário e três deles são abordados neste texto: a identificação da educação com a escolaridade, a 
limitação do direito absoluto à educação ao nível fundamental e a falta de discussões sobre as formas assumidas pela educação.

\section{Identificação da educação com a escolaridade}

Nos tratados internacionais os direitos, via de regra, são expressos como princípios e as estratégias para que eles sejam postos em vigor ficam a cargo de cada Estado. O direito à educação, entretanto, tem a sua realização condicionada por um meio especial, qual seja, a instituição escolar (e, em menor escala, a universidade). A palavra "escola" não consta do Artigo 26, mas as categorias fundamental, técnico-profissional e superior deixam clara a sua presença. Em documentos posteriores, como a Declaração de Jomtien e os Comentários Gerais ao Artigo 13 do PIDESC, faz-se distinção entre ensino primário e ensino fundamental ${ }^{3}$, sendo este entendido como o direito e aquele, como o sistema de ofertas. Na prática, ambos se combinam, e de fato interpretações desse direito (BEITER, 2006; COOMANS, 2007) e campanhas dele oriundas o interpretam como escola 4 .

Do ponto de vista estratégico, o foco na escola pode ser considerado lógico, já que esta constitui um método de oferta de instrução testado e experimentado com um vasto número de crianças. Apesar de o seu formato atual ter origem europeia, a instituição escolar se espalhou pelo mundo, seja por adoção consciente, seja por imposição colonial, e o seu reconhecimento é praticamente universal. A escola também facilita o monitoramento do acesso e do desempenho. Por outro lado, igualar a educação à escolaridade tem uma limitação óbvia. Se imaginarmos ambas em um diagrama de Venn, veremos que uma parte significativa de cada uma se situa fora do domínio da outra. Muito do que se passa na escola não é educação (por exemplo, o ato de tomar conta das crianças, a garantia de alimentação, os cuidados de saúde e algumas tarefas menos agradáveis, como controle social e doutrinação, sem esquecer o que Dore (1976, p. xi) chama de "mero ganho de qualificação"), e grande parte do processo educativo não se dá na escola ou universidade, mas nas famílias, grupos comunitários, instituições religiosas, bibliotecas, campanhas políticas, etc.

\footnotetext{
${ }^{3}$ Coomans (2007, p. 199) define que a Educação Fundamental inclui "alfabetização, aritmética, habilidades relacionadas a saúde, higiene e cuidados pessoais e habilidades sociais, tais como expressão oral e resolução de problemas", bem como aspectos referentes ao respeito pelos direitos humanos.

${ }^{4}$ De acordo com Verheyde (2006), a CNUDC omite sobre a questão da educação formal e não formal, a despeito de o comitê formado para monitorar a convenção entender que o direito se refere a ambas as modalidades de educação. A Declaração de Jomtien também reconhece o papel da educação não formal em conjunto com a educação formal (Artigo V).
}

No contexto da busca pela Educação Para Todos, há duas fortes razões para que educação e escolaridade não sejam igualadas. Em primeiro lugar, muitas escolas ao redor do mundo não conseguem oferecer uma experiência que possa ser chamada efetivamente de educação. Entre muitos exemplos possíveis, cito o estudo etnográfico de Palme (1999) sobre escolas no norte de Moçambique, o qual proporciona uma imagem viva, e também desalentadora desse fato. Os alunos passam a maior parte do tempo ouvindo sem entender, copiando sem entender e simplesmente esperando. Em muitos países, a pesquisa quantitativa sobre os resultados da aprendizagem oferece um quadro igualmente sombrio dos efeitos da escolaridade (por exemplo, WATKINS, 2000; WORLD BANK, 2006). Além de poder não ter quase nenhum significado, a escola pode ser positivamente prejudicial. No estudo de Palme, considera-se que o descompasso entre a escola e a comunidade local leva à desvalorização e ao repúdio extremos da última por parte dos poucos sobreviventes do percurso escolar. Esta longa passagem é digna de nota:

Visto que as práticas de ensino atuais, com poucas exceções, reiteram a passividade dos alunos e que o uso do português como única língua de instrução impõe grandes limitações ao entendimento conceitual e à troca verbal, praticamente não se estabelece... uma comunicação entre os conceitos prévios dos alunos e as novas informações e experiências que lhes são passadas na sala de aula ou pelo livro didático. Assim, não surpreende que os poucos que conseguem sobreviver ao ciclo escolar ao longo dos anos são profundamente transformados pelo processo educativo e, devido à amnésia geral produzida pela natureza dessa transformação, normalmente passam a conceber o mundo moderno e educado no qual conseguiram se inserir como totalmente diferente e superior ao mundo retrógrado do qual vieram. (PALME, 1999, p. 267).

O estudo de Serpell (1999) sobre o papel da escolaridade na África reafirma esse extremo descompasso:

O resultado dessa formalização da educação é que alguns indivíduos com grande potencial para contribuir para a vida das suas comunidades de origem são sistematicamente postos numa cultura de poder burocrático alheia a tudo, ao passo que a maioria dos alunos matriculados abandona a escola com um sentimento de frustração e inadequação. (SERPELL, 1999, p. 132-133).

Ademais, muitas atividades e experiências vivenciadas pelas crianças nas escolas não somente não cumprem o direito à educação como representam abusos de outros direitos humanos (WILSON, 2004). Tais abusos encontram-se bem documentados em pesquisas empíricas, como na de Unterhalter (2003) sobre violência sexual contra 
meninas em escolas sul-africanas e as suas relações com a contaminação pelo vírus HIV:

Para jovens negras sul-africanas ir à escola não significa uma possibilidade de alcançarem seus potenciais, mas pode muito bem estar colocandoas sob o grave risco de sofrerem terríveis traumas, serem infectadas e morrerem precocemente. (UNTERHALTER, 2003, p. 16).

Disso se conclui que é possível haver violações dos direitos humanos quando nativos e grupos étnicos minoritários (e, em alguns contextos póscoloniais, também grupos étnicos majoritários) ficam sujeitos a sistemas de educação formal que, na meIhor das hipóteses, ignoram as suas culturas ou, na pior, as reprimem com veemência. A escolaridade também se mostra violadora de direitos quando as crianças, em razão de provas decisivas e outros tipos de pressão, são submetidas a longas horas de estudo e sofrem grande estresse (SPRING, 2000).

Evidentemente, isso não significa que a escolaridade é uma experiência desprovida de sentido ou danosa para todas as crianças em todos os países de baixa ou média renda. Para muitos dos alunos a escola, mesmo em condições não favoráveis, constitui uma experiência inspiradora e até libertadora que abre horizontes e possibilita oportunidades até então não imaginadas. O problema é que isso não se aplica a todos os alunos. Assim, o direito à educação não pode ser igualado ao direito ao acesso à escola, nem mesmo se acrescentarmos o epíteto "de qualidade" ao termo "escola". O fato é que a escola pode satisfazer o direito à educação, mas não é uma condição necessária nem suficiente para isso.

Por outro lado, considerando-se que nem toda escolaridade assegura direitos, deve haver meios pelos quais o direito à educação é assegurado mesmo na ausência de um sistema educacional formal ${ }^{5}$. Como já mencionado, a educação se dá em meios muito distintos, tais como programas de aprendizes, organizações voluntárias e o contexto de cada comunidade local. Iniciativas educacionais fora do ambiente escolar, geralmente identificadas como "educação não formal", compreendem ao mesmo tempo experiências que simulam esse ambiente para aqueles que se encontram alijados dele e experiências de aprendizagem de natureza e formato muito diversos (HOPPERS, 2007; ROGERS, 2004; ROSE, 2007). A fim de avaliar se o direito à educação está de fato sendo preservado nessas iniciativas, é necessário examinar com mais atenção o conceito de educação, o que será feito nas seções finais deste artigo.

\footnotetext{
${ }^{5}$ Para os propósitos deste estudo a educação formal é tomada como sinônimo de escolaridade, seja propiciada pelo Estado ou por uma instituição privada, embora Rogers (2004) mostre que há dificuldades substanciais em estabelecer uma definição que diferencie a educação formal da educação não formal.
}

\section{Limitação do direito absoluto}

Além de fazer referência ao Ensino Fundamental, o Artigo 26 da DUDH deixa claro que o Ensino técnico-profissional e o Ensino Superior devem ser acessíveis a todos, este último com base no mérito. Entretanto, somente o ensino fundamental é visto como direito absoluto ${ }^{6}$ e as justificativas para esse fato não parecem ser convincentes. Do ponto de vista da qualificação, o diploma de conclusão do Ensino Fundamental não tem muita utilidade numa sociedade em que as pessoas cada vez mais têm acesso ao ensino médio e à universidade. Poderíamos dizer que o domínio básico da leitura, da escrita e dos principais conceitos matemáticos, o qual pode ser adquirido nas séries iniciais, é a porta para funções-chave na sociedade. No entanto, não há uma linha divisória precisa nesse caso, pois a habilidade de ler e escrever não é algo que simplesmente possuímos ou não, mas uma prática que desenvolvemos permanentemente ao longo das nossas vidas e que nos confere mais influência e oportunidades à medida que progredimos. Quaisquer que sejam os critérios, é difícil estabelecer uma lógica para esse contexto. Tratando-se de conhecimento de mundo, habilidades analíticas, comunicação, desenvolvimento estético e outras competências, é difícil determinar o ponto em que a educação deixa de ser um direito e passa a ser apenas um bem. Com esta colocação, não estamos sugerindo que rejeitamos a noção do direito à educação, mas que reconhecemos que esse direito tem uma aplicação muito mais ampla do que normalmente se pensa.

Existem nítidas razões de ordem prática para que o direito à educação seja restrito ao Ensino Fundamental: é uma meta perfeitamente atingível, visto que a instituição é claramente reconhecida e a conquista do acesso universal pode ser monitorada com relativa facilidade. Em alguns casos, o Ensino Fundamental constitui um ciclo em si próprio, não sendo apenas uma preparação para os níveis mais avançados. Ainda nessa perspectiva pragmática, deve-se destacar que no momento não é viável que os países mais pobres financiem o acesso universal ao Ensino Médio, do mesmo modo que está além das possibilidades da maioria dos países mais ricos financiar o acesso universal ao Ensino Superior. Portanto, há várias boas razões para se considerar o Ensino Fundamental o direito universal decisivo, mas essa estratégia pragmática não pode ser confundida com um direito moral. Em boa parte das esferas da vida, uma pessoa com Ensino Fundamental completo provavelmente estará em grande desvantagem perante aquelas que estudaram por 12 anos ou mais. Há também fortes argumentos a favor de que

\footnotetext{
${ }^{6}$ A realização gradual desse direito, mesmo no nível fundamental, é aceita no caso de países com insuficientes recursos.
} 
a educação pré-escolar seja considerada um direito, dada a sua importância fundamental para o posterior desenvolvimento da criança (UNESCO, 2006) ${ }^{7}$. Além disso, se há um direito humano à educação, parece apropriado aplicá-lo não somente a todos os níveis de educação formal como ao longo de toda a vida.

\section{A natureza da educação}

Um aspecto intimamente ligado aos dois itens anteriores é o fato de que o Artigo 26 pouco esclarece acerca do que a educação deve englobar. São mencionados alguns objetivos possíveis da educação, a saber:

- O pleno desenvolvimento da personalidade
humana;
- O fortalecimento do respeito pelos direitos
humanos e pelas liberdades fundamentais;

- A promoção da compreensão, da tolerância e da amizade entre todas as nações e grupos raciais ou religiosos;

- O auxílio às atividades das Nações Unidas em prol da manutenção da paz.

É interessante notar que, conquanto os direitos devam estar relacionados antes de tudo aos interesses do seu detentor individual, os objetivos explicitados no artigo, à exceção do primeiro, referem-se, sobretudo a interesses societários e globais, embora naturalmente também tragam benefícios para os indivíduos. Poderíamos questionar a escolha de objetivos, a omissão de outros e o modo vago como foi exposta a ideia de "desenvolvimento da personalidade humana", mas o mais grave é que não são mencionadas as características do processo educacional nem os meios pelos quais este deve ou não ser conduzido. Os Comentários Gerais feitos posteriormente revelam um quadro mais detaIhado desses objetivos e destacam uma importante restrição de métodos: a abolição do castigo físico (fato também enfatizado na CNDUC). A Convenção sobre a Eliminação de Todas as Formas de Discriminação contra as Mulheres (1979) também aborda questões ligadas aos processos educacionais, como a coeducação, os retratos de gênero e os métodos de ensino.

No entanto, via de regra, tais declarações de direitos não mencionam o que de fato a educação envolve. Esse silêncio é destacado por Spring (2000), que relembra a crítica feita por Isaac Kandel, já em 1947, sobre a conceituação do direito à educação. A questão-chave levantada por Kandel, discutida nos parágrafos anteriores em relação à es-

\footnotetext{
${ }^{7}$ O Artigo 18 da CNUDC apoia de forma limitada o direito à educação e a cuidados na primeira e na segunda infância.
}

colaridade, diz respeito a como o direito ao acesso à educação pode resultar na violação de outros direitos. Nesse contexto, o autor deu especial atenção à doutrinação nacionalista, mas também apontou a segregação racial e o aumento das desigualdades entre as classes sociais. Mesmo que a DUDH considere o ato de "promover a compreensão, a tolerância e a amizade entre todas as nações" um requisito para a educação, não é dada atenção aos modos como o ensino e a aprendizagem acontecem. Fica claro que deve haver restrições quanto ao que pode ser tomado como método educacional, tanto em termos de considerações morais quanto em termos de consistência com o conceito de educação, como argumentou Peters (1966). O respeito pelos direitos humanos e pela dignidade de todos os seres humanos é sem dúvida um objetivo desejável no processo educacional de jovens, mas claramente não é suficiente estabelecer esse objetivo e imaginar que os problemas relacionados ao conteúdo da educação foram resolvidos. Tampouco está claro se esse objetivo pode ser alcançado por meio da educação e, caso possa, como pode sê-lo.

Portanto, embora seja conveniente do ponto de vista pragmático, a escolaridade é em última análise uma base inadequada para o direito à educação. Por outro lado, cabe a pergunta: é possível, sem um foco institucional, conceituar o tipo de educação subjacente ao direito universal?

\section{Um direito a quê?}

O acesso à escolaridade, como base do direito à educação, é um fator ligado aos "insumos". Poderíamos ir além e definir o tipo de currículo, a infraestrutura física e o quadro de professores qualificados necessários para o cumprimento desse direito, porém, conforme mostraram as discussões sobre a qualidade da educação (por exemplo, Alexander, 2008), em geral o problema de se concentrar em fatores ligados aos insumos é que isso nos informa muito pouco sobre como os recursos são usados e que resultados eles acarretam. Há, portanto, outros dois aspectos da educação que podem servir como candidatos a base do direito em questão: os resultados da educação e os próprios processos educacionais.

\section{Resultados da aprendizagem}

Dados os problemas decorrentes do foco exclusivo no acesso às escolas de nível fundamental, à primeira vista os resultados da aprendizagem parecem um candidato muito promissor a base do direito à educação. Em vez de focarem os insumos, muitas agências internacionais estão usando indicadores de resultados para medir o progresso rumo 
aos objetivos da Educação Para Todos. O Banco Mundial tem dado atenção especial aos resultados da aprendizagem (sobretudo na forma de habilidades cognitivas), vendo-os em grande medida como sinônimo de qualidade da educação (HANUSHEK; WOESSMANN, 2007; VEGAS; PETROW, 2008; WORLD BANK, 2006). Esse tipo de abordagem também ganhou popularidade no formato "educação baseada em resultados", introduzido em vários países, incluindo-se Austrália e África do Sul.

De maneira geral, os resultados que receberam maior atenção foram os desempenhos dos alunos em provas de Matemática, Ciências e língua materna, mas, apesar de tais indicadores poderem facilitar comparações internacionais, é óbvio que habilidades específicas avaliadas em provas escritas num único momento não servem como parâmetros de resultados educacionais. Como aponta Hahn (1987, p. 229), além de provas de rendimento, podemos utilizar vários outros elementos para medir o sucesso do processo educacional, inclusive a "observação de crianças interagindo na área de recreação com colegas pertencentes a outros grupos culturais ou de jovens dispostos a ensinar membros da sua comunidade sobre os seus direitos". Evidentemente, alguns resultados educacionais, como a alfabetização, as habilidades analíticas e a habilidade de comunicação, são pré-requisitos para uma vida plena. Por outro lado, há problemas relacionados à identificação do direito à educação com resultados específicos da aprendizagem, quaisquer que sejam os tipos. Dois deles são descritos brevemente neste texto.

\section{a) Determinando o nível de resultado}

É difícil determinar níveis de resultado específicos que fariam parte de um direito. Como já discutido acerca da natureza problemática da limitação do direito à educação à escolaridade fundamental, qualquer nível que seja estipulado é passível de questionamento. Poderíamos dizer, por exemplo, que existe um direito à alfabetização básica (deixando de lado por um momento como isso seria definido), mas na maioria das sociedades a falta de um domínio avançado da leitura e da escrita limitaria seriamente o acesso de um indivíduo a trabalhos valorizados e a estudos avançados, assim como a sua apreciação de muitas formas de arte e entretenimento. É difícil dizer com segurança que há um direito à alfabetização básica e não à alfabetização avançada. Portanto, os resultados só podem ser propostos em termos muito gerais.

Outro problema é que, por implicação, o direito à educação termina quando determinado objetivo é alcançado. Por exemplo, se uma criança em idade precoce aprendesse a ler e a escrever em casa, não haveria um direito que lhe garantisse o desenvolvimento dessas habilidades. Se, por outro lado, víssemos os resultados em termos de habilidades cognitivas específicas, a criança em idade precoce detentora dessas habilidades simplesmente não teria direito à educação. Apesar de ser muito desafiador na prática, o direito à educação deveria ter pelo menos uma aplicabilidade permanente. Num nível mais profundo, engana-se quem entende a aprendizagem como um conjunto de resultados fixos de conhecimentos, habilidades e valores; na verdade, trata-se de uma experiência fluida, de desenvolvimento constante. A educação não nos leva a determinado ponto, é um processo contínuo.

b) $O$ efeito limitador dos resultados

Há um problema adicional causado pelo uso de metas e objetivos na educação (JANSEN, 1998; MCCOWAN, 2009). Nas sociedades contemporâneas, existe uma tendência de se ver a educação como um meio de atingir metas bem variadas, tanto no plano nacional quanto no individual. Contudo, metas não podem ser impostas facilmente à educação dessa maneira, o que se deve em parte à natureza intrinsecamente imprevisível da educação. Além disso, subordinar a educação a metas específicas pode ter um efeito limitador nos processos educacionais. A educação, por oposição ao treinamento, condicionamento e doutrinação, é caracterizada pela abertura, e atrelá-la a resultados específicos limitará o seu potencial. Obviamente, isso não significa dizer que a educação deve ser desprovida de metas ou propósitos; ao contrário, é impossível conceber a educação sem propósitos. Como argumenta Dewey (1916), as metas devem surgir da natureza dos processos educacionais e ser coerentes com a mesma, e professores e aprendizes devem participar da sua elaboração.

É absolutamente correto haver metas educacionais como alfabetização, competência financeira, consciência da história da comunidade e do mundo e por aí adiante. Também é válido que a conquista de determinados resultados cognitivos seja um critério de qualidade na educação, entre outros. Ainda que essas sejam metas válidas para a educação, a sua conquista não pode ser a base do direito à educação.

\section{Processos educacionais}

Em lugar dos resultados da aprendizagem, deve-se dar atenção aos processos educacionais nos quais os alunos se engajam. $O$ direito à educação, nesse caso, seria, por exemplo, o engajamento em processos de desenvolvimento da alfabetização, e não a conquista de um nível específico de alfabetização. Por exemplo, seria possível tomar como referência uma situação em que os alunos se põem a pesquisar um problema ambiental local 
que coloca em evidência vários conhecimentos, habilidades e valores, em contraponto a uma situação em que os conceitos a serem aprendidos são estabelecidos previamente. Esse foco nos permite evitar a problemática tarefa de determinar resultados específicos, entendendo que as experiências educacionais não são demasiadamente restritas por objetivos predefinidos e que nós não somos forçados a estipular este ou aquele nível de rendimento. Como mostrado nos parágrafos anteriores, sempre há (e sempre deve haver) propósitos para os esforços educacionais, de modo que poderíamos dizer que nesse caso haveria um direito aos processos que contêm propósitos ${ }^{8}$.

Além das vantagens educacionais de evitar uma abordagem baseada em objetivos - por exemplo, possibilitar a criatividade pedagógica e as respostas dos alunos, elementos que, embora imprevistos, são valiosos (ver STENHOUSE, 1975) -, há uma razão adicional para que os processos devam estar no centro do direito à educação. Os direitos humanos precisam ser um conjunto coerente: enquanto são feitas distinções entre direitos absolutos e direitos prima facie, numa declaração como a DUDH não deve haver trocas necessárias - os direitos podem, pelo menos em tese, ser preservados ao mesmo tempo. (Na prática, quando os países trabalham para preservar os direitos universais, pode haver decisões referentes à possibilidade de determinado direito ser trabalhado primeiramente). Essa compatibilidade essencial com os demais direitos torna altamente relevante o modo como a educação é conduzida. Com a ênfase recente nas abordagens de desenvolvimento baseadas nos direitos, agências internacionais estão corretamente dispensando mais atenção à conservação dos direitos humanos no âmbito da educação (UNICEF/UNESCO, 2007). Conforme já discutido, Wilson (2004) relata brevemente várias maneiras pelas quais as práticas contemporâneas de escolaridade violam os direitos humanos, incluindo a discriminação contra minorias e deficientes, 0 tratamento degradante dado a crianças e a falta de reconhecimento dos direitos dos professores. A literatura sobre os 4 As (por exemplo, TOMASEVSKI, 2003 , 2006) do direito à educação também destaca os princípios aos quais as práticas educacionais devem estar conformadas, sobretudo no que se refere à aceitabilidade (questões de doutrinação, censura em livros didáticos, meio de instrução, castigo físico etc.) e à adaptabilidade (em relação à idade, à habilidade, ao gênero, à religião etc.).

Os estudos citados acima identificam restrições-chave ao que pode ser tomado como práticas educacionais no âmbito do direito à educação - nos

\footnotetext{
8 Poderíamos ainda querer estipular a identificação universal desses propósitos, mas o direito à educação não se destina $a$ satisfazê-los.
}

dizeres de Wilson (2004, p. 3), "um limite menor à qualidade". No entanto, há também maneiras positivas de pensarmos a realização da educação. Em qualquer forma de educação que envolva valores, os princípios contidos nos fins devem ser de alguma maneira materializados nos meios (MCCOWAN, 2009). Nesse caso, a implicação é que os direitos humanos, o respeito por eles e o seu ativo exercício devem ser incorporados ao processo educacional. De fato, a DUDH conclama a educação a promover o respeito pelos direitos humanos, mas essa situação é distinta porque se trata de um resultado proposto, e não um princípio que se pretende como norteador dos próprios processos educacionais. Em vez disso, os meios devem surgir dos fins para que os valores (dignidade humana, participação ativa, liberdade de expressão etc.) que formam a base dos direitos humanos sejam preservados nos processos educacionais.

Nas abordagens atuais, os processos são em grande parte ignorados. A Declaração de Jomtien enfatiza sobretudo os resultados da aprendizagem:

Em consequência, a educação básica deve estar centrada na aquisição e nos resultados efetivos da aprendizagem, e não mais exclusivamente na matrícula, frequência aos programas estabelecidos e preenchimento dos requisitos para a obtenção do diploma (Artigo IV).

Em relação à natureza dos resultados, a declaração propõe que todas as pessoas devem adquirir certas habilidades e conhecimentos em preparação para a vida, mas não os define com precisão. É verdade que em alguns trechos atenta para os processos, mas o faz subordinando-os aos resultados:

\begin{abstract}
Abordagens ativas e participativas são particularmente valiosas no que diz respeito a garantir a aprendizagem e possibilitar aos educandos esgotar plenamente suas potencialidades. Daí a necessidade de definir, nos programas educacionais, os níveis desejáveis de aquisição de conhecimentos e implementar sistemas de avaliação de desempenho (Artigo IV).
\end{abstract}

Um recente relatório que dá a devida atenção aos processos realizados dentro da escola foi elaborado pela UNICEF/UNESCO (2007), com princípios de direitos humanos aplicados ao currículo, à pedagogia e à avaliação, apoiando-se no fato de que "uma abordagem de educação baseada em direitos requer atenção simultânea ao resultado e aos processos" (UNICEF/UNESCO, 2007, p. 15).

Todavia, dar ênfase ao processo implica dificuldades. É muito mais difícil monitorar do que enfocar, digamos, a matrícula na escolaridade fundamental ou resultados específicos de aprendizagem. Além disso, permanece a tarefa de determinar quais processos educacionais são 
válidos, uma questão essencial que não pode ser abordada neste artigo.

\section{Um direito de duas vias}

Unterhalter e Brighouse (2007), em sua análise da justiça social e da Educação Para Todos, identificam três esferas coincidentes do benefício da educação: a intrínseca (que aumenta a qualidade de vida por meio do desenvolvimento educacional em si), a instrumental (que possibilita o acesso ao trabalho e outras oportunidades) e a posicional (que constitui as oportunidades de uma pessoa em relação a outras na sociedade). É essencial reconhecer todos esses aspectos da escolaridade e as suas implicações para a justiça na sociedade. A esfera intrínseca da educação é visivelmente a base para o direito à educação, pois tal direito só existe se possui algum valor intrínseco. Se o seu valor estivesse baseado na sua contribuição para, por exemplo, as habilidades profissionais ou a participação política, os direitos em questão seriam os do trabalho e da participação política, e a educação não passaria de estratégia para a realização destes. Além disso, como destacam Snook e Lankshear (1979, p. 36),

[s]e a educação for justificada instrumentalmente, qualquer reivindicação de um direito à educação terá por base a justeza do modelo de meios e fins. O elo permanecerá empírico e poderá ser quebrado por mudanças que venham a ocorrer no mundo.

Entretanto, os aspectos instrumentais também são basilares, e a educação age como um condutor dos demais direitos, reforçando as capacidades das pessoas de atuarem e terem influência sobre o mundo ao seu redor (WRINGE, 1986). É ainda relevante ter em mente a importância da escolaridade para a reparação de desigualdades históricas relacionadas a gênero, raça e classe social. Contudo, conceber o direito à educação na perspectiva da esfera posicional é uma tarefa que gera complicações, no sentido de que existe um direito universal à vantagem posicional em relação a outros. Por exemplo, um dos aspectos-chave da posicionalidade é a certificação, sendo as qualificações essenciais para oportunidades e influência na maioria das sociedades contemporâneas. Porém, é difícil incluí-las no direito à educação porque elas normalmente atuam como um mecanismo de distribuição no mercado de trabalho e nos níveis mais altos da educação, de modo que torná-las universalmente disponíveis destruiria a sua raison d'être. Embora não haja um direito a qualificações, poderíamos argumentar que há um direito que assegura que a chance de conquistá-las e as oportunidades possibilitadas por elas não sejam negadas de maneira injusta. Assim, as pessoas teriam o direito de não sofrer desvantagem posicional devido à escolaridade (ou à falta desta).
Algumas ilustrações empíricas são úteis neste ponto. King-Calneck (2006), por exemplo, explora o trabalho educativo desenvolvido pelo grupo de percussão Olodum. Além do seu trabalho musical, o Olodum desenvolve programas educacionais como parte da sua ampla missão, que inclui divulgar a identidade e a música afro-brasileiras, fazer campanhas contra a discriminação e prevenir a adesão de jovens negros ao crime e às drogas. Tais atividades são gratuitas e destinam-se tanto a crianças em idade pré-escolar quanto a adolescentes e adultos jovens que tenham abandonado a escola. Embora por um período o Olodum tenha oferecido aulas convencionais de ensino fundamental, na maior parte as atividades educacionais têm sido desenvolvidas paralelamente ao sistema formal. Os alunos podem estudar informática e inglês e se dedicar a atividades culturais, como pintura, música e teatro de marionetes, tudo embebido de cultura e história afro-brasileiras. Esse enfoque permite que as crianças entendam e desenvolvam atitudes positivas para com a sua origem, a qual, apesar das recentes garantias legais, é normalmente ignorada ou desvalorizada no currículo escolar tradicional. É evidente que essas atividades preenchem o direito à educação mediante o aumento do conhecimento e do entendimento que as crianças têm da sua cultura e o desenvolvimento de habilidades profissionais e da capacidade de desfrutar a vida plenamente por meio da expressão cultural e artística, possibilitada por processos educacionais que respeitam os seus direitos humanos.

No entanto, não há chance de essas crianças e suas famílias escolherem essa forma de educação em lugar do sistema formal. Na verdade, há evidências substanciais em todo o mundo de que os pais são resistentes à ideia de trocar a educação formal pela não formal, até mesmo quando esta última é mais significativa, relevante, agradável e efetiva. No estudo de Dyer (2000) sobre pastores rabáris do oeste da Índia, a comunidade rejeitou a educação não formal itinerante que surgiu em conformidade com os seus padrões de trabalho em favor da educação formal sedentária, a despeito de as escolas formais serem tidas como de baixa qualidade. É evidente que as vantagens posicionais adquiridas com o sistema formal são consideradas indispensáveis em muitos casos, inclusive na ausência de aprendizagem significativa. Há também uma ideia de que a iniciação nos rituais esotéricos da escolaridade formal possibilita a compreensão de outros rituais esotéricos pertencentes à sociedade burocrática moderna:

Os pais reiteravam que as suas crianças deveriam "melhorar" (sudhare) e se tornar "espertas" (hoshiar), qualidades que os rabáris associam a pessoas que frequentam as escolas formais. Além 
disso, as escolas são vistas como lugares aonde as pessoas vão para aprenderem "a falar". Aparentemente, saber "falar" representa para os rabáris a libertação dos sentimentos de impotência e intimidação perante as instituições modernas. (DYER, 2000, p. 246).

Portanto, é possível propor dois direitos independentes relacionados à educação, ou dois aspectos do direito à educação:

1) O direito de se engajar em processos educacionais que sejam intrínseca e instrumentalmente valiosos e que englobem o respeito pelos direitos humanos;

2) $\mathrm{O}$ direito de acesso às instituições e experiências educacionais que conferem vantagem posicional.

É válido lembrar que, a despeito de a infância ser uma fase de especial importância, o primeiro direito aplica-se a toda a vida. Escolas e universidades podem ter um papel efetivo na preservação desse direito, mas não se pode esperar que seja assim em todos os casos. Ademais, deve-se destacar que há muitas precondições necessárias para que as pessoas participem plenamente dos processos educacionais, tais como nutrição, saúde e segurança adequadas, o que enfatiza a interdependência dos diferentes conjuntos de direitos humanos. Evidentemente, experiências de aprendizagem valiosas também podem ser conquistadas em vários outros contextos. No entanto, a educação informal e não formal raramente conduz ao tipo de certificação que garante vantagem posicional aos alunos, e na maioria das sociedades o sucesso na educação formal é a chave para os melhores empregos e outras boas oportunidades. Não importa o quanto nem o que se aprenda mediante a educação não formal, pois na maioria das sociedades o diploma é indispensável para as melhores oportunidades. Isso significa que o direito à educação precisa incluir um componente relacionado ao aspecto distributivo da educação formal. Na verdade, é o primeiro aspecto o que constitui a essência do direito à educação em si; o segundo aspecto é dependente da maneira como os sistemas educacionais são organizados na maior parte das sociedades contemporâneas e do quanto o "sucesso" desses sistemas é determinante para outras oportunidades.

\section{Concretizando o duplo direito}

Esta reformulação do direito à educação nos dá três alternativas para o desenvolvimento das oportunidades educacionais na sociedade. Em primeiro lugar, os procedimentos para o acesso ao emprego e a estudos superiores poderiam ser alterados de tal modo que a certificação conferida pela educação formal deixasse de ser necessária (como proposto por DORE, 1976). Essas alterações tornariam desnecessária a segunda parte do direito à educação, permitindo a concentração de esforços na aprendizagem significativa. Contudo, apesar da grande expansão das qualificações e dos efeitos nocivos da doença do diploma, é altamente improvável que esse tipo de mudança ocorra em alguma parte do mundo; há inclusive indícios de que está ocorrendo justamente o contrário.

Em segundo lugar, a educação poderia ser reformada de tal modo que forneça, além da almeja certificação, as experiências necessárias para uma aprendizagem significativa, sempre em harmonia com outros direitos humanos. Esforços consideráveis estão sendo feitos nesse sentido em todo o mundo, muitos associados com a mais do que desejada ênfase na "qualidade da educação", após o entusiasmo inicial com o foco na matrícula no ensino fundamental. Entretanto, a instituição escolar mostra-se altamente resistente a reformas, a despeito de algumas exceções significativas (ver FARRELL; HARTWELL, 2008).

Em terceiro e último lugar, a estratégia é aceitar o fato de que a educação formal é ao mesmo tempo bastante almejada por conta da certificação que confere e repleta de falhas no que se refere à provisão de experiências de aprendizagem. Portanto, a solução seria garantir que as pessoas tenham acesso tanto a uma educação formal quanto a uma educação não formal de alta qualidade. Nesse caso, os dois aspectos do direito à educação seriam garantidos por dois tipos de instituição ou experiência, uma solução que pode não ser ideal, apresentando muitos desafios em termos de oferta, mas no momento é talvez a opção mais viável.

Robeyns (2006, p. 70) afirma que:

Um discurso sobre direitos pode induzir os legisladores a ficarem satisfeitos quando seguem estritamente as regras que lhes são impostas por uma interpretação limitada desses direitos, até mesmo quando esforços adicionais se fazem necessários para se atingir o objetivo subjacente a determinado direito.

Embora não constitua uma razão para se abandonar uma abordagem baseada em direitos, a proposta delineada por Robeyns realmente destaca a necessidade de se redefinir o direito à educação enfatizando o papel central do engajamento em processos educacionais que são significativos e respeitam os direitos humanos.

O conceito proposto neste artigo nos dá motivos tanto para celebrar quanto para lamentar. Por um lado, muito do que se passa nas escolas não auxilia o direito à educação; por outro, há práticas educacionais, vigentes inclusive nos países mais pobres, que cumprem essa função em conjunto com 
a escolaridade formal ou até mesmo na ausência desta. As nossas ações precisam ser direcionadas para o encorajamento - e para o entendimento mais profundo - dessas práticas, onde quer que elas ocorram.

\section{Referências}

ALEXANDER, R. Education for all, the quality imperative and the problem of pedagogy. CREATE Pathways to Access, Research Monograph n. 20. Brighton: Centre for International Education, University of Sussex, 2008.

BEITER, K. The protection of the right to education by international law. Leiden: Martinus Nijhoff Publishers, 2006.

COOMANS, F. Content and scope of the right to education as a human right and obstacles to its realization. In: DONDERS, Y.; VOLODIN, V. (Eds.). Human rights in education, science and culture: legal development and challenges. Paris and Aldershot: UNESCO Publishing/Ashgate, 2007.

CURREN, R. Education as a social right in a diverse society. Journal of Philosophy of Education, v. 43, n. 1, p. 45-56, 2009.

DOI: $10.1111 /$ j.1467-9752.2008.00663.x

DEWEY, J. Democracy and education. New York: MacMillan, 1916.

DORE, R. The diploma disease: education, qualification and development. London: George Allen \& Unwin, 1976.

DYER, C. "Education for All" and the Rabaris of Kachchh, Western India. International Journal of Educational Research, v. 33, n. 3, p. 241-251, 2000. DOI:10.1016/ S0883-0355(00)00012-4

FARRELL, J.; HARTWELL, A. Planning for successful alternative schooling: a possible route to education for all. Research Papers IIEP. Paris: IIEP, 2008.

FRIBOULET, J. J.; NIAMEOGO, A.; LIECHTI, V.; DALBERA, C.; MEYER-BISCH, P. Measuring the right to education. Fribourg: Schulthess, 2006.

HAHN, C. The right to a political education. In: TARROW, N. (Ed.) Human rights and education. Oxford: Pergamon, 1987.

HANUSHEK, E.; WOESSMANN, L. Education quality and economic growth. Washington, D. C.: World Bank, 2007.

HODGSON, D. The human right to education. Dartmouth: Ashgate, 1998.

HOPPERS, W. Meeting the learning needs of all young people and adults: an exploration of successful policies and strategies in non-formal Education. Background Paper prepared for the GMR 2008. Paris: UNESCO, 2007.
JANSEN, J. Curriculum reform in South Africa: a critical analysis of outcomes-based education. Cambridge Journal of Education, v. 28, n. 3, p. 321-331, 1998. DOI: $10.1080 / 0305764980280305$.

KING-CALNEK, J. Education for citizenship: interethnic pedagogy and formal education at Escola Criativa Olodum. Urban Review, v. 38, n. 2, p. 145-164, 2006. DOI: $10.1007 / s 11256-006-0028-4$

MCCOWAN, T. Rethinking citizenship education: a curriculum for participatory democracy. London: Continuum, 2009.

PALME, M. Cultural ambiguity and the primary school teacher: lessons from Rural Mozambique. In: LEACH, F.; LITTLE, A. (Eds.). Education, cultures, and economics: dilemmas for development. New York: Falmer Press, 1999.

PETERS, R. S. Ethics and education. London: Allen \& Unwin, 1966.

POGGE, T. World poverty and human rights: cosmopolitan responsibilities and reforms. Cambridge: Polity, 2002.

ROBEYNS, I. Three models of education: rights, capabilities and human capital. Theory and Research in Education, v. 4, n. 1, p. 69-84, 2006. DOI: $10.1177 / 1477878506060683$

ROGERS, A. Non-formal education: flexible schooling or participatory education? Hong Kong: CERC, University of Hong Kong, 2004.

ROSE, P. NGO provision of basic education: alternative or complementary service delivery to support access to the excluded? CREATE Pathways to Access, Research Monograph n. 3. Brighton: Centre for International Education, University of Sussex, 2007.

SEN, A. Elements of a theory of human rights. Philosophy and Public Affairs, v. 32, n. 4, p. 315-356, 2004. DOI: 10.1111/j.1088-4963.2004.00017.x

SERPELL, R. Local accountability to rural communities: a challenge for educational planning in Africa. In: LEACH, F.; LITTLE, A. (Eds.). Education, cultures, and economics: dilemmas for development. New York: Falmer Press, 1999.

SNOOK, I.; LANKSHEAR, C. Education and rights. Melbourne: Melbourne University Press, 1979.

SPRING, J. The universal right to education: justification, definition, and guidelines. New Jersey: Lawrence Erlbaum, 2000.

STENHOUSE, L. An introduction to curriculum research and development. London: Heinemann Educational, 1975.

TOMASEVSKI, K. Education denied: costs and remedies. London: Zed Books, 2003.

. Human rights obligations in education: the 4-A scheme. Nijmegen: Wolf Legal Publishers, 2006.

UNESCO. Challenges of implementing free primary 
education in Kenya: assessment report. Nairobi: UNESCO Nairobi Office, 2005.

Strong foundations: early childhood care and education. EFA Global Monitoring Report 2007. Paris: UNESCO, 2006.

Overcoming inequality: why governance matters. EFA Global Monitoring Report 2009. Paris: UNESCO, 2008.

UNICEF/UNESCO. A human rights-based approach to education for all. New York: UNICEF/UNESCO, 2007.

UNTERHALTER, E. The capabilities approach and gendered education: an examination of South African Complexities. TheoryandResearch inEducation, v.1,n. 1, p. 7-22, 2003. DOI:10.1177/1477878503001001002

UNTERHALTER, E.; BRIGHOUSE, H. Distribution of what for social justice in education? The case of Education for All by 2015. In: WALKER, M.; UNTERHALTER, E. (Eds.). Amartya Sen's capability approach and social justice in education. New York: Palgrave Macmillan, 2007.

VANDENBERG, D. Education as a human right: a theory of curriculum and pedagogy. New York: Teachers College Press, 1990.

VEGAS, E.; PETROW, J. Raising student learning in Latin America: the challenge for the 21st century. Washington, D. C.: World Bank, 2008.

VERHEYDE, M. Article 28: the right to education. Leiden: Martinus Nijhoff Publishers, 2006.

WATKINS, K. The oxfam education report. Oxford: Oxfam, 2000.

WILSON, D. A human rights contribution to defining quality education. Background paper prepared for the education for all Global Monitoring Report 2005. Paris: UNESCO, 2004.

WORLD BANK. From schooling access to learning outcomes: an unfinished agenda. An analysis by the independent evaluation group of the World Bank. Washington, D. C.: World Bank, 2006.

WRINGE, C. The human right to education. Educational Philosophy and Theory, v. 18, n. 2, p. 23-33, 1986. DOI: 10.1111/j.1469-5812.1986.tb00415.x

Recebido em 29/12/2010

Aceito em 15/03/2011 